\title{
VALIDITY AND RELIABILITY OF SHIFT WORK DISORDER QUESTIONNAIRE AMONG INDONESIAN FEMALE NURSES
}

\author{
Anggi Setyowati ${ }^{1,5}$, Ah. Yusuf ${ }^{2}$, Setya Haksama ${ }^{3}$ and Syamsul Firdaus ${ }^{4}$ \\ ${ }^{1}$ Doctoral Student, Public Health Faculty, Universitas Airlangga, Surabaya, Indonesia, \\ ${ }^{2}$ Department of Community and Mental Health Nursing, Faculty of Nursing, Universitas Airlangga, Surabaya, Indonesia \\ ${ }^{3}$ Department of Health Administration and Policy, Public Health Faculty, Universitas Airlangga, Surabaya, Indonesia \\ ${ }^{4}$ Nursing Department, Poltekkes Kemenkes, Banjarmasin, Indonesia \\ ${ }^{5}$ Universitas Cahaya Bangsa, Banjar, Sout Kalimantan, Indonesia
}

Correspondence author: Ah. Yusuf

E-mail address: ah-yusuf@fkp.unair.ac.id

\begin{abstract}
Nurses on shift work experience several symptoms such as excessive sleep, insomnia, feeling tired and fatigue. This situation could be inimical to health, and lead to the conditions known as shift work disorder (SWD). A tool is needed to measure shift work disorder among shift work nurses. It can be used to understand the ailment, and support strategies to prevent it. The aim of this study was to adapt SWD questionnaire for use in Bahasa. The study was a cross-sectional study among 201 female nurses who worked on shift duties at public hospital from March to April 2020. The questionnaires were self-administered via an online platform. SWD questionnaire was measured using three questions from previous study. It was used to measure sleep disorder related to work schedule. Permission to use this questionnaire was granted by original author. The process of translation and adaptation SWD questionnaire based on WHO studies. Cronbach alpha was used to measure internal consistency reliability. Exploratory factor analysis (EFA) using principal axis factor to examine construct validity. Confirmatory factor analysis (CFA) was used to assess the structural model fit of SWD. The cronbach alpha for SWD questionnaire was 0.834, which indicated adequate reliability. All of the items in SWD questionnaire had factor loading greater than 0.32, and the CR and AVE of SWD questionnaire were 0.951 and 0.751 , which indicated good convergent validity. This study validates the psychometric properties of SWD questionnaire among Indonesia Female Nurses, including translation, validity, and reliability.
\end{abstract}

Keywords: psychometric, shift work disorder, validity, reliability

\section{INTRODUCTION}

Nurses on shift work experience several symptoms such as excessive sleep, insomnia, ${ }^{1,2}$ tiredness and fatigue, ${ }^{3}$ and impaired health. ${ }^{4}$ In addition, shift worker nurses tend to have effective sleep less than eight hours per day. ${ }^{5}$ This may worsen existing health conditions and even cause SWD. ${ }^{6}$

Signs and symptoms of shift work disorder are sleeping excessively or falling asleep at work, ${ }^{7}$ poor performance, fatigue, and insomnia. ${ }^{8}$ Shift work disorder occurred due to work schedule. Prevalence of shift work disorder among nurses in Norway is $32.4 \%-37.6 \% .{ }^{9}$ In Brazil, more than $50 \%$ of nurses experience severe sleep disorders. ${ }^{10}$ In Indonesia, the prevalence of sleep disorders among nurses is $52.50 \%{ }^{11}$. Shift work disorder among nurses had effect on patient safety as well as work accident, ${ }^{12}$ in addition shift work disorder among nurse had adverse effect on mental health such as depression and anxiety ${ }^{13}$ as well as physical health such as cardiovascular disease and all cause specific mortality. ${ }^{14}$

To prevent negative effect on shift work disorder, a tool is needed to measure shift work disorder among shift work nurses. It can be used to understand the sleep disorder among shift workers and develop strategies to prevent shift work disorder. ${ }^{15,16}$ This tool is also needed for clinical purpose, especially for rapid screening. ${ }^{17}$ Original shift work disorder (SWD) questionnaire can be used to assess shift work disorder among shift workers ${ }^{1}$, it was consisted three items and the criteria based on International Classification of Sleep Disorder, second edition. ${ }^{18}$ However it has not been translated and adapted for use in Bahasa. Those, the aim of this study was to adapt original shift work disorder (SWD) questionnaire into Bahasa, including translation, validity, and reliability instrument. 


\section{METHODOLOGY}

Ethical clearance this study was obtained from Research Ethics Committee of the Faculty of Nursing, Universitas Airlangga, Indonesia, with number 1903-KEPK. This was cross-sectional study. After obtaining the informed consent forms, we distributed online self-reported questionnaires, and only researchers who can access the questionnaires. We ensured the confidentiality of respondents. The participants were allowed to withdraw during study, and they got voucher after completing the questionnaires. Previous study suggested that minimum sample to get adequate statistic was 200 ${ }^{19}$ or five cases per free parameter in the model 20 22. We had three parameters in this study, so the minimum sample in this study was 15 respondents. The data was collected from a 201 female shift work nurses who work at public hospital In Banjarmasin, South Kalimantan, Indonesia, from March to April 2020. The inclusion criteria for the participants were adult between 20-45 years old and work with shift work system (morning shift, afternoon shift, and night shift).

Shift work disorder (SWD) questionnaire was measured using three questions from previous study. ${ }^{1}$ It was used to measure sleep disorder related to work schedule. Permission to use this questionnaire was granted by original author. 1 Original SWD questionnaire contains three items, with yes or no answer format. Shift work disorder criteria was obtained if the respondents answer "yes" to all these questions. The three questions were: 1. Difficulties with sleep or excessive sleepiness, 2. Sleep and sleepiness related to work schedule, 3. Sleep or sleepiness related to work schedule persist for at least one month. ${ }^{1}$ This original SWD questionnaire was selected because the criteria of this questionnaire was selected based on International Classification of Sleep Disorder, second edition. ${ }^{1,18}$

The process of translation and adaptation of SWD questionnaire based on WHO studies and previous study ${ }^{23}$. The first step was forward translation from English to Bahasa: one expert translator who knew English but mother tongue was bahasa translated the original instrument into Bahasa. Then, we conducted back translation from Bahasa to English by a professional translator, the back translator never seen the original shift work disorder questionnaire. Then we conducted pilot study and finally we obtained final version of SWD questionnaire in Indonesian language (bahasa). ${ }^{23,} 24$

SPSS was used to analyze the data. We used descriptive statistic such as mean and standard deviation for summarising continuous variables. Cronbach alpha was used to measure internal consistency using reliability analysis in SPSS. Previous studies suggest that cronbach's alpha $>0.5$ is considered accepted reliability ${ }^{25-27}$. Exploratory factor analysis (EFA) using principal axis factor was employed to examine construct validity. KMO and Bartlett;s test of sphericity were used to asses factor analysis. ${ }^{28}$ The KMO must be greater than 0.6 and Bartlett; $s$ test of sphericity must be significant $(p<0.05) .20,29$ Convergent validity was evaluated using factor loading $>0.32,{ }^{30}$ composite reliability $(\mathrm{CR})>0.6$, and average variance extracted (AVE) > 0.4. ${ }^{31}$ Confirmatory factor analysis (CFA) was used to assess the structural model fit of SWD questionnaire Indonesia version. The following fit indices were evaluated using goodness-of-fit index (GFI), comparative fit index (CFI), and incremental fit indices (IFI) should be greater than 0.9.29 Convergent validity was calculated using pearson correlation, by examining the relationship between each item and total score of SWD questionnaire Indonesia version. ${ }^{16}$

\section{RESULTS}

Table 1 showed the distribution of respondent characteristic. This study included 201 female shift work nurses with a mean age of 27.7 years old. Most respondents had vocational diploma of nursing $(56.2 \%)$ and predominantly had work experience more than 5 years (54.2\%). Most of respondents ever switch shift with others due to personal reasons (97.5\%).

The quantitative data of SWD questionnaire Indonesia version: mean, standard deviation, cronbach's alpha and item total correlation coefficient were presented in Table 2.

\section{Reliability estimate: Internal consistency} The cronbach alpha for SWD questionnaire Indonesia version was 0.834 and ranged from 0.721 to 0.853 when an item was deleted. 
Table 1: Distribution of respondent characteristic

\begin{tabular}{|c|c|c|c|c|}
\hline $\begin{array}{l}\text { Demographic } \\
\text { characteristics }\end{array}$ & Category & n (\%) & $\begin{array}{l}\text { Non Shift work } \\
\text { disorder }\end{array}$ & $\begin{array}{c}\text { Shiftwork } \\
\text { disorder }\end{array}$ \\
\hline Age (years) Mean (SD) & & $27.7(3.8)$ & & \\
\hline \multirow[t]{5}{*}{ Level of Education } & Vocational & $113(56.2)$ & 92 & 21 \\
\hline & $\begin{array}{c}\text { Bachelor of } \\
\text { nursing }\end{array}$ & $14(7.0)$ & 6 & 8 \\
\hline & Registered nurse & $72(35.8)$ & 54 & 18 \\
\hline & Master of nursing & $2(1.0)$ & 2 & 0 \\
\hline & Total & $201(100)$ & 154 & 47 \\
\hline \multirow{4}{*}{$\begin{array}{l}\text { Work Experience } \\
\text { (months) }\end{array}$} & $12-35$ & $67(33.3)$ & 52 & 15 \\
\hline & $36-60$ & $25(12.5)$ & 21 & 4 \\
\hline & $>60$ & $109(54.2)$ & 81 & 28 \\
\hline & Total & $201(100)$ & 154 & 47 \\
\hline \multirow[t]{3}{*}{ Quick return } & Yes & $31(15.4)$ & 24 & 7 \\
\hline & No & $170(84.6)$ & 130 & 40 \\
\hline & Total & $201(100)$ & 154 & 47 \\
\hline \multirow{3}{*}{$\begin{array}{l}\text { Change shift with } \\
\text { others }\end{array}$} & Yes & $196(97.5)$ & 150 & 46 \\
\hline & No & $5(2.5)$ & 4 & 1 \\
\hline & Total & $201(100)$ & 154 & 47 \\
\hline
\end{tabular}

Table 2. SWD Questionnaire Analysis

\begin{tabular}{lcccc}
\hline SWD & Mean & SD & $\begin{array}{c}\text { Cronbach's Alpha } \\
\text { if Item deleted }\end{array}$ & Item total r \\
\hline $\begin{array}{l}\text { Item 1 } \\
\text { Do you experience difficulties with } \\
\text { sleeping or excessive sleepiness? }\end{array}$ & 0.363 & 0.48 & 0.853 & $0.823^{*}$ \\
$\begin{array}{l}\text { Item 2 } \\
\text { Is the sleep or sleepiness problem } \\
\text { related to a work schedule where } \\
\text { you have to work when you would } \\
\text { normally sleep? }\end{array}$ & 0.378 & 0.48 & 0.730 & $0.888^{*}$ \\
$\begin{array}{l}\text { Item 3 } \\
\text { Has this sleep or sleepiness } \\
\text { problem related to your work } \\
\text { schedule persisted for at least one } \\
\text { month? }\end{array}$ & 0.338 & 0.47 & & \\
Global score & & & & 0.721 \\
\hline * value & 1.079 & 1.25 & & \\
\hline
\end{tabular}

Factor structure of SWD questionnaire

An exploratory factor analysis was performed to evaluate the construct validity of SWD questionnaire Indonesia version. The result of Kaiser-Meier-Olkin test was and the Bartlett's test value of sphericity was statistically significant $(p<$ 0.001). All of the items in SWD questionnaire Indonesia version had factor loading greater than 0.32 , which indicated good convergent validity (Table 3).

\section{Construct validity}

Table 3 showed the CR and AVE of SWD questionnaire Indonesia version were 0.951 and 0.751 , respectively, which indicated acceptable convergent validity. Confirmatory factor analysis (CFA) was assessed to validate the structure of SWD questionnaire Indonesia version. Figure 1 showed the goodness of fit for the model structure with goodness-of-fit index $(\mathrm{GFI})=0.978$, comparative fit index $(\mathrm{CFI})=0.922$, incremental fit indices $(\mathrm{IFI})=$ 0.924 . 
Table 3. Factor loading for explanatory factor analysis

\begin{tabular}{lrrrr}
\hline \multicolumn{4}{c}{ Shift Work Disorder } \\
\hline & Factor loading & AVE & CR \\
\hline Item 1 & 0.656 & & 0.753 & 0.951 \\
Item 2 & 0.797 & & & \\
Item 3 & 0.806 & & \\
\hline
\end{tabular}

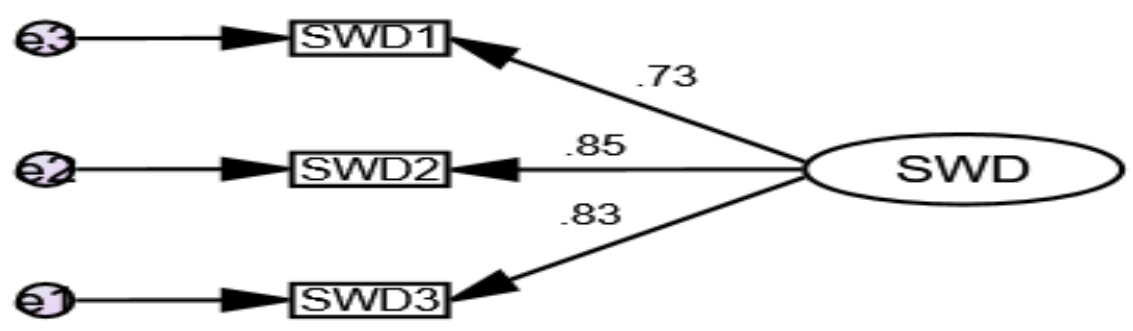

Figure 1. The Factor structure of SWD; goodness-of-fit index $(\mathrm{GFI})=0.978$, comparative fit index $(\mathrm{CFI})=$ 0.922 , incremental fit indices (IFI) $=0.924$

\section{DISCUSSION}

This study evaluated the psychometric of shift work disorder (SWD) questionnaire Indonesia version consisting of translation, validity, and reliability among female shift work nurses in Indonesia. SWD questionnaire Indonesia version had adequate validity and reliability. The internal consistency of SWD questionnaire Indonesia version was adequate with cronbach's alpha $=0.834$. Previous studies showed that Conbach's alpha $>0.5$ was acceptable. ${ }^{25,26}$

Convergent validity of SWD questionnaire Indonesia version was good, the positive correlation between each item and total score was more than $0.2^{32}$ also it had factor loading greater than $0.32 .{ }^{30}$ SWD questionnaire Indonesia version was also supported by construct validity. EFA (exploratory factor analysis) was used to analyze dimension of shift work disorder questionnaire Indonesia version and it produced one dimension. This study also conducted Confirmatory Factor Analysis (CFA) to address the construct validity. Shift work disorder questionnaire Indonesia version had adequate convergent validity based on AVE and CR in table 3. Figure 1 showed that the model structure of shift work disorder questionnaire Indonesia version had fit indices, specifically GFI, CFI, and IFI.

This study showed that SWD questionnaire Indonesia version is a stable instrument to measure shift work disorder. This tool can be used for screening shift work disorder among female nurses. ${ }^{1}$ In addition, this tool can be used in a research setting. The limitation of this study was we only focused on construct validity and did not compare SWD questionnaire Indonesia version to the other scales, therefore further study is needed to compare with other scale to measure shift work disorder.

\section{CONCLUSIONS}

This study evaluated the psychometric properties of SWD questionnaire Indonesian version including translation, validity, and reliability. This questionnaire can be used to assess shift work disorder among shift work nurses.

\section{Acknowledgement}

We would like to thank for the funding from Ministry of Research and Technology / National Research and Innovation Agency, Indonesia.

\section{REFERENCES}

1. Eldevik MF, Flo E, Moen BE, et al. Insomnia, excessive sleepiness, excessive fatigue, anxiety, depression and shift work disorder in nurses having less than 11 hours inbetween shifts. PloS one. 2013;8(8):e70882. https://doi.org/10.1371/journal.pone.0070 882 
2. Zhan Y, Liu Y, Liu H, et al. Factors associated with insomnia among Chinese front-line nurses fighting against COVID-19 in Wuhan: A cross-sectional survey. Journal of nursing management. 2020;28(7):1525-35. https://doi.org/10.1111/jonm.13094

3. Min A, Min H, Hong HC. Work schedule characteristics and fatigue among rotating shift nurses in hospital setting: An integrative review. Journal of nursing management. 2019;27(5):884-95. https://doi.org/10.1111/jonm.12756

4. Ferri P, Guadi M, Marcheselli L, et al. The impact of shift work on the psychological and physical health of nurses in a general hospital: a comparison between rotating night shifts and day shifts. Risk management and healthcare policy. 2016;9:203. https://dx.doi.org/10.2147\%2FRMHP.S115 326

5. Rhéaume A, Mullen J. The impact of long work hours and shift work on cognitive errors in nurses. Journal of nursing management. 2018;26(1):26-32. https://doi.org/10.1111/jonm.12513

6. Fadeyi BA, Ayoka AO, Fawale $M B$, et al. Prevalence, predictors and effects of shift work sleep disorder among nurses in a Nigerian teaching hospital. Sleep Science and Practice. 2018;2(1):6. https://doi.org/10.1186/s41606-018-0027$\mathrm{x}$

7. Åkerstedt T. Shift work and disturbed sleep/wakefulness. Occupational medicine. 2003;53(2):89-94. https://doi.org/10.1093/occmed/kqg046

8. Schwartz JR. Recognition of shift-work disorder in primary care. Journal of Family Practice. 2010;59(1):S18-S.

9. Haile KK, Asnakew S, Waja T, et al. Shift work sleep disorders and associated factors among nurses at federal government hospitals in Ethiopia: a cross-sectional study. BMJ open. 2019;9(8):e029802. https://doi.org/10.1136/bmjopen-2019029802
10. Guerra PC, Oliveira NF, Len CA. Sleep, quality of life and mood of nursing professionals of pediatric intensive care units. Revista da Escola de Enfermagem da USP. 2016;50(2):279-85.

http://dx.doi.org/10.1590/S0080623420160000200014

11. Nugroho A, Sulistomo A, Roestam AW. Asscociation between Workshift Pattern (2 Shift and 3 Shift) with Sleep Quality in Nurses at Two Military Hospitals-Jakarta (A Study Using PSQI Quesionner). Journal of The Indonesian Medical Association Majalah Kedokteran Indonesia. 2018;68(1).

12. Åkerstedt $T$, Wright KP. Sleep loss and fatigue in shift work and shift work disorder. Sleep medicine clinics. 2009;4(2):257-71. https://doi.org/10.1016/j.jsmc.2009.03.001

13. Kalmbach DA, Pillai V, Cheng $P$, et al. Shift work disorder, depression, and anxiety in the transition to rotating shifts: the role of sleep reactivity. Sleep medicine. 2015;16(12):1532-8. https://doi.org/10.1016/j.sleep.2015.09.00 7

14. Jørgensen JT, Karlsen S, Stayner L, et al. Shift work and overall and cause-specific mortality in the Danish nurse cohort. Scandinavian journal of work, environment \& health. 2017:117-26. https://doi.org/10.5271/sjweh.3612

15. Abdulmalik JO, Sale S. Pathways to psychiatric care for children and adolescents at a tertiary facility in northern Nigeria. Journal of public health in Africa. 2012;3(1). https://dx.doi.org/10.4081\%2Fjphia.2012.e 4

16. Setyowati A, Chung $M-H$, Yusuf A. Development of self-report assessment tool for anxiety among adolescents: Indonesian version of the Zung self-rating anxiety scale. Journal of Public Health in Africa. 2019;10(s1).

https://doi.org/10.4081/jphia.2019.1172

17. Tzeng JI, Fu Y-W, Lin C-C. Validity and reliability of the Taiwanese version of the Pittsburgh Sleep Quality Index in cancer 
patients. International journal of nursing studies. 2012;49(1):102-8. https://doi.org/10.1016/j.ijnurstu.2011.08. 004

18. Medicine AAoS. International classification of sleep disorders. Diagnostic and coding manual. 2005:51-5.

19. Quintana SM, Maxwell SE. Implications of recent developments in structural equation modeling for counseling psychology. The Counseling Psychologist. 1999;27(4):485527.

https://doi.org/10.1177\%2F001100009927 4002

20. Tabachnick BG, Fidell LS, Ullman JB. Using multivariate statistics: Pearson Boston, MA; 2007.

21. Kline RB. Principles and practice of structural equation modeling: Guilford publications; 2015.

22. Chou C-P, Bentler PM. Estimates and tests in structural equation modeling. 1995.

23. Setyowati $A$, Chung $M H$. Validity and reliability of the Indonesian version of the Pittsburgh Sleep Quality Index in adolescents. International Journal of Nursing Practice. 2020:e12856. https://doi.org/10.1111/ijn.12856

24. WHO. Process of translation and adaptation of instruments 2014 [cited 201121 May]. Available from: https://www.who.int/substance_abuse/res earch_tools/translation/en/.

25. Morera OF, Stokes SM. Coefficient $\alpha$ as a measure of test score reliability: Review of 3 popular misconceptions. American journal of public health. 2016;106(3):458-61. https://dx.doi.org/10.2105\%2FAJPH.2015.3 02993

26. Streiner DL. Starting at the beginning: an introduction to coefficient alpha and internal consistency. Journal of personality assessment. 2003;80(1):99-103. https://doi.org/10.1207/S15327752JPA800 1_18

27. Setyowati $A$, Chung $M-H$, Yusuf $A$, et al. Psychometric of the curiosity and exploration inventory-ii in Indonesia. Journal of Public Health Research. 2020;9(3).

https://doi.org/10.4081/jphr.2020.1745

28. Coakes SJS, L.G. SPSS analysis without anguish version 11 for windows Milton, QLD: John Wiley and Sons Australia2003.

29. Hair JF, Anderson RE, Tatham RL, et al. Multivariate data analysis. Upper Saddle River, NJ: Prentice Hall; 1998.

30. Comrey AL, Lee HB. A First Course in Factor Analysis, 2nd Edn. Hillsdale, NJ: L. Erlbaum Associates; 1992.

31. Huang $\mathrm{C}-\mathrm{C}$, Wang $\mathrm{Y}-\mathrm{M}, \mathrm{Wu} \mathrm{T}-\mathrm{W}$, et al. An empirical analysis of the antecedents and performance consequences of using the moodle platform. International Journal of Information and Education Technology. 2013;3(2):217.

32. Kline P. A Handbook of Test Construction: Introduction to Psychometric Design. New York: Methuen. Inc; 1986. 